\title{
USO DE CLORPROMAZINA PARA TRATAMENTO DE CEFALÉIA NO SERVIÇO DE EMERGÊNCIA
}

\author{
AGNALDO R. DA COSTA*, PAULO HÉLIO MONZILLO**, WILSON LUIZ SANVITO***
}

\begin{abstract}
RESUMO - Quatorze pacientes foram avaliados no serviço de emergência da Santa Casa de São Paulo devido a cefaléia aguda. Quatro pacientes tinham o diagnóstico de enxaqueca com aura e cinco o de enxaqueca sem aura. Quatro pacientes foram diagnosticados como portadores de cefaléia crônica diária com interparoxismos de enxaqueca. E finalmente um paciente tinha o diagnóstico de hemicrania paroxística crônica. Todos os pacientes receberam diagnóstico de acordo com os critérios da International Headache Society, para a cefaléia que motivou a procura do atendimento de emergência. A dose de clorpromazina usada foi $0,7 \mathrm{mg} / \mathrm{Kg}$ diluída em solução glicosada a $5 \%$ e a dose máxima nunca excedeu $50 \mathrm{mg}$. O tempo de administração nunca foi inferior a 60 minutos. Os resultados foram considerados excelentes em todos os casos. Alguns pacientes apresentaram efeitos colaterais, particularmente hipotensão ortostática, sempre moderada e transitória. Este estudo demonstra claramente que a clorpromazina $(0,7 \mathrm{mg} / \mathrm{Kg})$ é altamente eficaz para tratamento de episódios de cefaléia primária.
\end{abstract}

PALAVRAS-CHAVE: cefaléia aguda, clorpromazina endovenosa, crises enxaquecosas.

\section{Intravenous chlorpromazine for the treatment of acute headache}

ABSTRACT - Therapeutic measures, with intravenous chlorpromazine, taken during acute headache are evaluated in fourteen patients at the emergency room in Santa Casa de São Paulo. Four patients had the diagnosis of migraine with aura and five patients migraine without aura. Four patients had diagnosis of chronic daily headache with intermittent and superimposed migrainous events. Finally one patient had the diagnosis of chronic paroxysmal hemicrania. All patients were diagnosed according to Intenational Headache Society criteria. The intravenous chlorpromazine dose used was $0.7 \mathrm{mg} / \mathrm{Kg}$ diluted in $5 \%$ glucose solution and the dose never exceeded $50 \mathrm{mg}$. The time of drug administration was never less than 60 minutes. The results were considered excellent in all cases. Some patients presented side effects, particularly orthostatic hypotension, always moderate and transitory. This study has clearlly demonstrated that intravenous chlorpromazine $(0.7 \mathrm{mg} / \mathrm{Kg})$ was highly effective in terminating episodes of primary headache.

KEY WORDS: acute headache, intravenous chlorpromazine, migraine attacks.

A cefaléia é seguramente uma das queixas mais frequentes na prática médica, sendo que uma parcela considerável dos pacientes necessita de atendimento de urgência em pelo menos um episódio durante a vida. Na sala de emergência a primeira questão que se impõe é definir se o paciente apresenta a cefaléia apenas como sintoma de alteração orgânica estrutural ou se, ao contrário, tem uma cefaléia-doença, denominador de um grupo chamado de cefaléias primárias justamente devido ao desconhecimento de sua etiopatogenia.

Este estudo tem como objetivo propor o uso de clorpromazina como alternativa terapêutica para o tratamento de cefaléia no serviço de emergência.

Estudo da Disciplina de Neurologia da Faculdade de Ciências Médicas da Santa Casa de São Paulo: *Professor Instrutor; **Professor Visitante; ***Professor Titular.

Dr. Agnaldo Rodrigues da Costa - Disciplina de Neurologia, Faculdade de Ciências Médicas, Santa Casa de São Paulo - Rua Dr. Cesário Motta Jr. 112 - 01221-020 São Paulo SP - Brasil. 


\section{CASUÍSTICA E MÉTODOS}

Quatorze pacientes admitidos no serviço de emergência da Santa Casa de São Paulo com queixa de cefaléia foram avaliados do ponto de vista clínico e clínico neurológico, sendo definidos como portadores de cefaléia primária segundo os critérios do Headache Classification Committee of the International Headache Society (IHS) ${ }^{1}$. Os pacientes apresentavam média de idade de 35,07 anos, com variação entre 22 e 54 anos, sendo nove do sexo feminino e cinco do masculino. Cinco pacientes apresentavam enxaqueca sem aura, quatro enxaqueca com aura, quatro cefaléia crônica diária em surto de agudização e uma paciente apresentava hemicrânia paroxística crônica que não vinha respondendo à terapêutica preconizada com indometacina. Tais pacientes foram avaliados quanto ao tempo de início da dor, que variava entre 30 minutos e quatro dias, e uso prévio de medicamentos para alívio da dor. A média de tempo de início de dor na admissão era 20,25 horas. Os medicamentos mais comumente utilizados pelos pacientes foram analgésicos comuns, derivados ergotamínicos, seguidos por antiinflamatórios não hormonais, dexametasona e sumatriptan, sendo que este último foi usado por duas vezes pelo mesmo paciente antes de procurar o serviço de emergência. Foram excluídos todos os pacientes que não preenchiam os critérios para o diagnóstico de cefaléia primária.

Os pacientes foram submetidos a infusão endovenosa de clorpromazina na dose de $0,7 \mathrm{mg} / \mathrm{Kg}$, diluída em soro glicosado a 5\%, em tempo nunca inferior a 60 minutos e dose total nunca superior a $50 \mathrm{mg}$, sendo mantidos em observação em decúbito por duas horas após o término da infusão.

\section{RESULTADOS}

Todos os pacientes submetidos à medicação apresentaram remissão completa da cefaléia durante a infusão da clorpromazina, predominantemente durante os primeiros trinta minutos da infusão. Quatro pacientes queixaram-se de sonolência, porém não pudemos evidenciar sedação excessiva em nenhum caso. Evidenciamos em um paciente, que havia feito uso prévio de metoclopramida, movimentos involuntários anormais do tipo coreo-atetósico que remitiram em menos de 24 horas após tratamento com biperideno, via oral, na dose de $2 \mathrm{mg}$ a cada 4 horas. Efeitos adversos como sudorese, náuseas ou vômitos não foram observados. Até onde tivemos notícia não houve recorrência da dor após administração da clorpromazina.

Três pacientes submetidos a este tratamento apresentaram, como efeito adverso à terapia, hipotensão ortostática, definida como declínio da pressão sistólica maior que $20 \mathrm{mmHg}$ logo após assumir a posição supina. Um destes pacientes desenvolveu intensa hipotensão ortostática, que não respondeu ao decúbito e que necessitou de infusão de solução salina a 0,9\% (1000 mL) para recuperação dos níveis pressóricos.

\section{DISCUSSÃO}

Cefaléia é uma queixa frequente, sendo que grande contingente populacional a referem pelo menos uma vez em sua vida, destes cerca de $40 \%$ experimentam recorrência da sintomatologia pelo menos uma vez ao ano. A incidência da cefaléia primária e por extensão de suas variantes demonstradas nesta pequena casuística não é muito bem definida. A cefaléia primária manifesta-se em geral de forma recorrente e em surtos (ou crises) podendo ter magnitude variável, necessitando de abordagem terapêutica imediata e adequada ${ }^{2}$.

Quando a dor tem fraca intensidade em geral analgésicos comuns e o repouso são suficientes para a remissão dos sintomas. No entanto quando é acentuada, como naqueles pacientes que procuram o serviço de emergência, tratamento mais agressivo deve ser considerado.

Os antiinflamatórios não-hormonais são considerados como drogas de primeira escolha para o tratamento. Atuam diminuindo a síntese de prostaglandinas e assim minimizam a atividade inflamatória neurologicamente mediada no sistema trigêmino-vascular. Postula-se que atuem também interferindo na neurotransmissão serotoninérgica e em geral diminuem a intensidade da dor de maneira marcante, porém usualmente não são capazes de interferir na duração da crise álgica. Como principais 
representantes deste grupo temos o naproxeno, o ibuprofeno e o ácido mefenâmico. Os seus efeitos adversos são fundamentalmente relacionados a sintomas dispépticos ${ }^{2}$.

Os derivados ergotamínicos e o sumatriptam têm mecanismo de ação semelhante, com afinidade pelo receptor de serotonina subtipo 5-HT1, tendo o sumatriptam alta afinidade pelo subtipo 5-HT1-D, receptores esses localizados nos terminais periféricos do trigêmeo que suprem as estruturas vasculares sensíveis à dor. A liberação de CGRP (calcitonin gene related peptide) é inibida pelo sumatriptan que também bloqueia a ativação do sistema trigêmino-vascular mediada por neuropeptídeos, havendo também ação direta vasoconstritora. Os ergotamínicos têm menor afinidade pelo receptor 5-HT1, porém têm maior atividade vasoconstritora, particularmente a diidroergotamina. Estas drogas são contraindicadas no infarto do miocárdio pregresso, insuficiência coronariana e hipertensão arterial sistêmica ${ }^{3}$.

Diversos antagonistas dopaminérgicos podem ser usados, com eficácia, no tratamento da enxaqueca. No entanto seu efeito sempre foi relacionado às ações antiemética, sedativa ou na motilidade gastrointestinal e não especificamente como possuidores de ação antienxaquecosa. A ativação dopaminérgica é um componente patofisiológico primário de certos tipos de enxaqueca, sendo demonstrado inclusive que os indivíduos enxaquecosos são mais suceptíveis à ativação dopaminérgica. Como exemplos pode-se observar que a infusão de baixas doses de apomorfina (5 $\mu \mathrm{g} / \mathrm{Kg}$ ) desencadeia respostas como o bocejo e o aumento do fluxo sanguíneo na artéria cerebral média ${ }^{4}$, enquanto pequenas doses de bromoergocriptina $(2,5 \mathrm{mg})^{5}$ podem desencadear hipotensão nestes indivíduos que é inibida por um antagonista periférico do receptor dopaminérgico D2 (DRD2) o domperidone, o que é explicado pela presença de receptores dopaminérgicos pré-sinápticos nos gânglios simpáticos noradrenérgicos ${ }^{6}$.

Outro fato que pode demonstrar que a função dopaminérgica está implicada nos mecanismos patofisiológicos da enxaqueca é a existência de entidades clínicas como a "Hemicrania choreoatetótica", pois sabemos de longa data que movimentos involuntários anormais encontramse relacionados a alterações da função dopaminérgica ${ }^{7}$. Dados de genética molecular têm demonstrado uma nova abordagem para o entendimento e manuseio desta desordem com importante componente genético. Em estudo recente um polimorfismo no gene que codifica o receptor dopaminérgico D2 (Nocardia corallina-I $\rightarrow \mathrm{Ncol}$ ) foi implicado no incremento da susceptibilidade nos portadores de enxaqueca, sendo mais significante nos portadores de enxaqueca com aura, o que suporta a hipótese que as bases patofisiológicas da enxaqueca podem ser modificadas por variações da função do DRD2 ${ }^{8}$. Quando as abordagens medicamentosas anteriores não são satisfatórias os agentes dopaminérgicos podem ser utilizados, em geral reservados para o tratamento de emergência de crises muito intensas e consideradas como intratáveis. $O$ haloperidol é um potente antagonista do receptor DRD2 e em recente estudo levou ao alívio ou remissão da dor entre 25 a 65 minutos após a infusão (5 mg EV aplicadas em apenas seis pacientes) ${ }^{9}$. A metoclopramida utilizada em infusão endovenosa na dose de $10 \mathrm{mg}$ demonstrou-se eficaz em $67 \%$ dos pacientes ${ }^{10}$. A proclorperazina demonstrou ser mais eficaz que o placebo, sendo um potente antagonista do receptor DRD2 ${ }^{11}$.

A clorpromazina em diferentes dosagens tem-se mostrado satisfatória, e endovenosamente na dose de $0,1 \mathrm{mg} / \mathrm{Kg}$ em 15 minutos é mais eficaz que a meperidina associada com dimenidrinato ${ }^{12}$. As hipóteses para sua eficácia e especificidade para este tipo de dor são: bloqueio adrenérgico; atividade anti-5-HT; ação anti-emética e modulação dos sistemas relacionados à dor (sistema límbico). Embora os dados anteriormente descritos pareçam apontar fundamentalmente para a sua atividade como antagonista dopaminérgico DRD2, pelo qual tem moderada afinidade. A clorpromazina tem grande capacidade de ligação protéica e consequente biodisponibilidade (80-96\%), tem meia vida de 16-30 horas e concentração plasmática eficaz entre 50-300 ng/ml, e sua metabolização é hepática apresentando pequena capacidade de indução enzimática. Como efeitos adversos podem apresentarse discinesia tardia, sudorese, náusea, vômito e hipotensão que é usualmente prevenida com o decúbito, e que na literatura são considerados como pouco comuns ${ }^{13,14}$. 


\section{CONCLUSÃO}

A clorpromazina pode ser usada para o tratamento de cefaléia primária em serviço de emergência, tem grande eficácia, baixo custo e efeitos colaterais que são potencialmente menos graves que os de outras drogas com as mesmas indicações. Dada a sua longa meia vida pode diminuir, pelo menos teoricamente, a recorrência dos sintomas em curto período de tempo.

Tem como inconveniente nesta forma de aplicação a necessidade de longo tempo de observação e de infusão que podem ser fatores limitantes para este tipo de abordagem em nosso meio. A casuística é ainda pequena mas pode já demonstrar que, na dose proposta, os efeitos benéficos quanto à remissão da dor são altamente positivos (100\% de remissão durante a infusão da droga). Deve ser considerada como alternativa terapêutica, particularmente nos casos em que abordagem anterior resultou inadequada ou em serviço de emergência quando a magnitude do processo doloroso é muito importante.

\section{REFERÊNCIAS}

1. Headache Classification Committee of the International Headache Society. Classification and diagnostic criteria for headache disorders, cranial neuralgias and facial pains. Cephalalgia 1988;8:1-96.

2. Welsh KMA. Drug therapy of migraine. N Engl J Med 1993;329:1476-1483.

3. Moskowitz MA. Neurogenic versus vascular mechanisms of sumatriptam and ergot alkaloids in migraine. Trends Pharmacol Sci 1992;13:307-311.

4. Blin O, Azulay J, Masson G, Aubrespey G, Serratice G. Apomorphine induced yawning in migraine patients: enhanced responsiveness. Clin Neuropharmacol 1990;13:264-267.

5. Fancioullacci M, Michelacci S, Curradi C, Sicuteri F. Hyperresponsiveness of migraine patients to the hypotensive action of bromocriptine. Headache 1980;17:129-102.

6. Peroutka SJ. Dopamine and migraine. Neurology 1997;49:650-656.

7. Bruin GW, Ferrari MD. Chorea and migraine: "hemicrania choreatetotica"? Chephalalgia 1984;4:120-124.

8. Peroutka SJ, Wilhoit T, Jones K. Clinical suceptibility to migraine with aura is modified by dopamine D2 receptor (DRD2) Ncol alleles. Neurology 1997;49:201-206.

9. Ficher H. A new approach to emergency therapy of migraine headache with intravenous haloperidol: a case series. J Emerg Med 1995;13:119-122.

10. Tek DS, McLellan DS, Olshaber JS, Allen CR, Arthur DC. A prospective double-blind study of metoclopramide hydrochloride for the control of migraine in the emergency department. Ann Emerg Med 1990; 19:1083-1087.

11. Jones S, Sklar P, Dougherty J, White W. Randomized double-blind trial of intravenous prochlorperazine for the treatment of acute headache. JAMA 1989;261:1174-1176.

12. Lane DL, McLellan BA, Baggoley CS. Comparative efficacy of chlorpromazine and meperidine with dimenhydrinate in migraine headache. Ann Emerg Med 1989;18:360-365.

13. Iserson KV. Parenteral chlorpromazine treatment of migraine. BMJ 1982;12:284-288.

14. Lane PL, Ross R. Intravenous chlorpromazine: preliminary results in acute migraine. Headache 1985;25:302-304. 